\title{
Inheritance of Resistance to Race 0 of Phytophthora parasitica var. nicotianae from the Flue-Cured Tobacco Cultivar Coker 371-Gold
}

\author{
Shawn R. Carlson and MaryAnne F. Wolff, Department of Crop Science; H. D. Shew, Department Plant Pathol- \\ ogy; and E. A. Wernsman, Department of Crop Science, North Carolina State University, Raleigh 27695-7620
}

\begin{abstract}
Carlson, S. R., Wolff, M. F., Shew, H. D., and Wernsman, E. A. 1997. Inheritance of resistance to race 0 of Phytophthora parasitica var. nicotianae from the flue-cured tobacco cultivar Coker 371-Gold. Plant Dis. 81:1269-1274.

Black shank, caused by Phytophthora parasitica var. nicotianae, is a widespread and severe disease of tobacco throughout the southeastern United States. Partial resistance derived from the cigar tobacco cultivar Florida 301 has been the primary means of reducing losses to the disease for many years. The recently released tobacco cultivar, Coker 371-Gold (C 371-G), was found to provide an additional source of resistance to P. parasitica var. nicotianae. Although the resistance in C $371-\mathrm{G}$ is being used widely by breeders, the origin and inheritance of this resistance mechanism was unknown. Two populations of doubled haploid lines derived from C 371$\mathrm{G}$ were used to determine that $\mathrm{C} 371-\mathrm{G}$ possesses a single, dominant gene designated $P h$, which confers a very high level of resistance to race 0 of $P$. parasitica var. nicotianae. A greenhouse inoculation procedure was developed that provided an efficient means of screening for the presence of this resistance gene prior to selection in the field, and confirmed that $P h$ provides complete resistance to race 0 but no resistance to race 1 of $P$. parasitica var. nicotianae. Because Florida 301 resistance is effective against both races of the pathogen that occur in the major tobacco growing areas of the United States, combination of these two sources of resistance should provide enhanced protection of new tobacco cultivars to P. parasitica var. nicotianae.
\end{abstract}

Yield losses from the soilborne pathogen Phytophthora parasitica (Dastur) var. nicotianae (Breda de Haan) Tucker (syn. Phytophthora nicotianae var. nicotianae) occur on all tobacco (Nicotiana tabacum L.) types produced throughout the world. $P$. parasitica var. nicotianae can infect tobacco roots, stems, and leaves at any stage of plant growth, resulting in wilting, stem lesions, and plant death (17). Losses to black shank can reach $100 \%$ if disease management practices are not used (26).

Incorporation of resistance genes into crop plants is a highly desirable means of controlling disease losses. Resistance derived from the cigar tobacco cultivar Florida 301 (Fla 301; 31) has been the principal source of resistance used to reduce losses to the black shank fungus in fluecured tobacco cultivars since the 1940s (1). This source of resistance has been incorporated subsequently into many cultivars of tobacco, where it provides partial resis-

Corresponding author: H. D. Shew

E-mail: d_shew@ncsu.edu

This work was supported by Philip Morris USA. SRC was supported by a Plant Molecular Biology fellowship from the North Carolina Biotechnology Center, Research Triangle Park.

Accepted for publication 22 July 1997.

Publication no. D-1997-0908-03R

(C) 1997 The American Phytopathological Society tance to $P$. parasitica var. nicotianae. The resistance reduces lesion number, slows the rate of root colonization, reduces inoculum production by $P$. parasitica var. nicotianae, and slows epidemic development $(9,10,12$, $13,20,21,24,25,27)$. The partial resistance of Fla 301 is thought to be controlled by several additive genes that are influenced by additional modifying genes $(5,6,33)$. Since its introduction, Fla 301 resistance has remained effective against known and unknown virulence phenotypes of $P$. parasitica var. nicotianae.

Tobacco breeders have recently employed another source of resistance derived from the flue-cured cultivar, Coker 371Gold (C 371-G; 7). This cultivar is highly resistant, but confusion about the pedigree of C 371-G has prevented the identification of the source of this resistance (8) and the nature of its inheritance. C 371-G provides complete resistance to race 0 of $P$. parasitica var. nicotianae but only a low to moderate level of resistance to race 1 of the same pathogen (19). Race 1 of P. parasitica var. nicotianae first was observed shortly after interspecific sources of resistance were introduced into tobacco germplasm (2,3). Additional races of $P$. parasitica var. nicotianae have been identified in other tobacco producing areas, but have not been observed in the United States $(18,19,22)$.

Race 0 is the predominant race of $P$. parasitica var. nicotianae in tobacco areas of North Carolina $(19,26)$. Race 1 occurs only when genotypes completely resistant to race 0 are planted, as in the burley tobacco region of North Carolina (16). Race 1 first became prevalent and destructive after only a single year of planting cultivars with single-gene, complete resistance to race 0 (3). Severity of losses to race 1 and the distribution of race 1 are unknown because of the widespread use of Fla 301 resistance, which is equally effective against all known races of the pathogen (17).

Screening for resistance to soilborne pathogens such as $P$. parasitica var. nicotianae often requires the maintenance of disease nurseries with high pathogen populations. Because inoculum levels and soil conditions often are variable throughout the field, numerous replications must be used to obtain reliable results. In addition, in temperate climates only one field test per year is possible. These factors often make field testing the limiting step in a breeding program for disease resistance (5).

Laboratory and greenhouse screening techniques for resistance are desirable because they give quicker results than field tests and are sometimes nondestructive. For example, a detached leaf technique was used to verify virus-resistant materials (23). However, detached leaf techniques have had limited accuracy in screens for most root pathogens, other than to identify extreme levels of resistance or susceptibility $(30,34)$. Stem inoculation techniques also have been used to screen for $P$. parasitica var. nicotianae resistance $(11,35)$, and although stem inoculation has shown higher correlation to field results than leaf tests, it may not reflect root responses to the pathogen (35). Both methods are often too variable to accurately screen for resistance within segregating tobacco populations.

Doubled haploid (DH) technologies also have been a valuable tool to aid tobacco breeders in development of desirable genotypes (5). Using this technique, haploid plants can be screened for disease resistance or other traits of interest. Chromosomes are doubled only for the selected genetic combinations to establish desired genotypes in completely homozygous lines. By identifying desirable genotypes early, fewer lines need be carried through successive generations. This early selection of lines also decreases the number of evaluations that must be conducted in a disease nursery, and the time required for cultivar development. 
The objectives of this study were to determine the inheritance of resistance to $P$. parasitica var. nicotianae in C 371-G, and to determine if a greenhouse inoculation procedure was an efficient means of selecting plants with this resistance. The greenhouse test then was used to assess the level of resistance provided by C 371-G against both races of $P$. parasitica var. nicotianae that occur in North Carolina.

\section{MATERIALS AND METHODS}

Plant genetic stocks. The flue-cured tobacco cultivar K 326 was chosen as a highyielding genotype with a low level of partial resistance to black shank derived from Fla 301. K 326 was hybridized with the highly resistant C 371-G. C 371-G also contains some or all of the Fla 301 genes for black shank resistance. $F_{1}$ progeny from this cross were hybridized as females with Nicotiana africana (Merxm and Buttler) to generate maternally derived haploids (4). These haploids were expected to contain the Fla 301 resistance genes present in both parents, but to segregate for any unique genes from C 371-G. The haploid plants derived from the hybridization were evaluated in a black shank field nursery naturally infested with race 0 of $P$. parasitica var. nicotianae. Chromosomes of plants with high resistance to $P$. parasitica

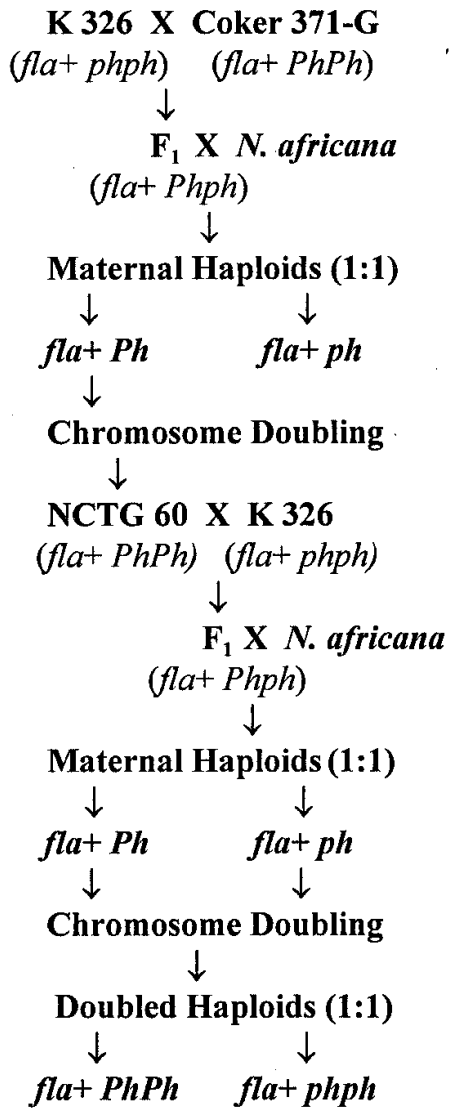

Fig. 1. Development of doubled haploid lines segregating for the qualitative resistance gene $\mathrm{Ph}$ from 'Coker 371-G' while maintaining partial resistance from 'Florida 301' (fla+). var. nicotianae were doubled using an in vitro midvein tissue culture technique (15). One of the high yielding lines selected, NCTG 60, was back-crossed once to the parent, K 326, and the $\mathrm{F}_{1}$ hybridized to $N$. africana to produce another segregating maternal haploid array (Fig. 1). Finally, chromosomes were doubled in a random sample of 19 haploid plants from this cross (maternal doubled haploid, DH), and selfpollinated seed was obtained from all lines. The DH lines were field-tested for disease response in a black shank nursery (5).

A second DH population, also segregating for the resistance derived from $\mathrm{C}$ 371$\mathrm{G}$, was initiated in the non-flowering (NF) tobacco breeding line NCTG 47 NF (32). Black shank resistance in NF tobaccos is derived from Fla 301, and is characteristically only a low level of partial resistance. The $F_{1}$ from the cross between NCTG 47 $\mathrm{NF}$ and $\mathrm{C} 371-\mathrm{G}$ was hybridized to $N$. afri$c a n a$, and a maternal haploid array was generated that was segregating for the resistance mechanism from C 371-G. Seven haploids were chosen and grown in a black shank disease nursery to assess the level of resistance present, and their chromosomes were then doubled. One DH line (designated DH 90-441-27) had both high black shank resistance and high yields.

Concurrently, a three-way-cross hybrid was obtained by hybridizing NC $27 \mathrm{NF}$ to the hybrid of NCTG $47 \mathrm{NF}$ and NC $37 \mathrm{NF}$. This three-way-cross hybrid then was used as the female parent in a cross with $N$. africana to generate maternal haploids. Chromosomes of 4 of the most desirable haploids were doubled to generate a series of $\mathrm{DH}$ lines designated DH 91-329-1 through 4. None of these lines carried black shank resistance. Hybridizations then were carried out between DH 90-441-27 and each of the
DH 91-329 lines. Four of these hybrids, which should have been heterozygous for $\mathrm{C}$ 371-G resistance, were evaluated in a disease nursery along with both parents.

Field evaluation. The DH parental lines, the hybrids between DH 90-441-27 and the DH 91-329 lines, and the DH lines derived from the NCTG 60 population were seeded, transplanted, and fertilized as conventional tobaccos in a black shank disease nursery in Oxford, North Carolina during 1992 and 1993. The nursery was naturally infested with race 0 of $P$. parasitica var. nicotianae. To monitor uniformity of $P$. parasitica var. nicotianae in the field, the black shank susceptible cultivar Hicks was interplanted between each row of these experimental lines. Lines were evaluated in two replications, each consisting of a 22-plant row, and scored for disease response biweekly following transplanting and throughout the entire growing season. Control lines, for comparison and to verify pathogen presence, included the susceptible and resistant parents for each cross. Individual plants were scored as susceptible following irreversible wilting, and highly resistant if there were no symptoms of black shank at the final disease reading (141 days after transplanting in 1992 and 114 days after transplanting in 1993). Any line with an average survival time of greater than 100 days was considered highly resistant. This limit was chosen to represent midseason leaf harvest in a normal tobacco growing season. Any line that survived more than 50 but less than 100 days in the disease nursery was considered to have low resistance.

Greenhouse design. Based on field response of the NCTG 60-derived DH population, 5 highly resistant lines and 5 lines with low resistance were chosen for

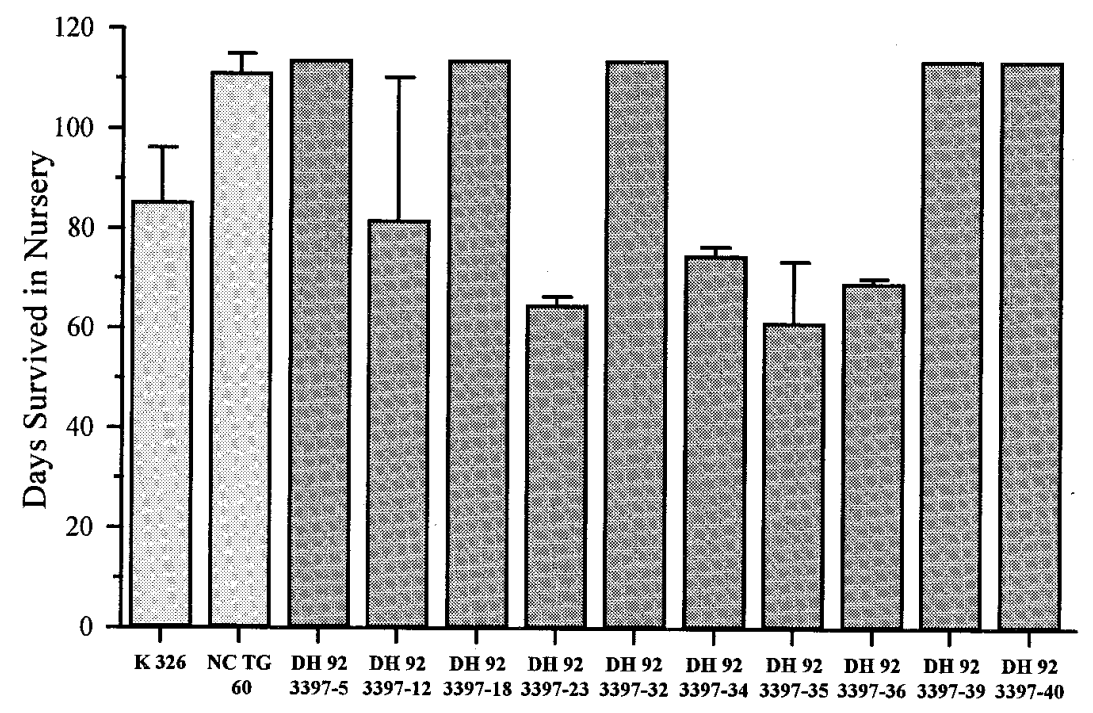

Fig. 2. Disease response of doubled haploid 92-3397 lines evaluated in a black shank disease nursery. K 326 is the susceptible check cultivar and NCTG 60 is the resistant check breeding line. Lines that survived greater than 100 days are considered highly resistant to Phytophthora parasitica var. nicotianae and homozygous for the $P h$ gene. Least significant difference ${ }_{0.05}=20.6$ for comparing any experimental line with resistant or susceptible check. 
each of two greenhouse tests. The 10 lines and parents (K 326, C 371-G, NCTG 60, and NCTG $60 \times \mathrm{K} 326$ ) were sown and maintained in a growth room at $26^{\circ} \mathrm{C}$ under $18 \mathrm{~h}$ of illumination. Six weeks after germination, seedlings of each line were transplanted individually into a 1:1 MetroMix:sterile sand medium in square, $8.5 \mathrm{~cm}$ plastic pots. Plants were moved into a greenhouse and randomized in a split-plot design with pathogen race as main plot and genotype as sub-plot. Six plants of each genotype were inoculated with race 0 and six with race 1 of $P$. parasitica var. nicotianae. Three plants from each genotype were left non-inoculated. The experiment was replicated twice.

Inoculum preparation and host inoculation. Pure cultures of $P$. parasitica var. nicotianae, race 0 from flue-cured tobacco and race 1 from burley tobacco were grown in the dark on $5 \%$ oatmeal agar in 9-cm-diameter petri dishes for 1 week prior to use. Inoculum for infesting the soil mix was prepared by blending the contents of 14 petri dishes, which contained fungal mycelium and agar medium, with 1 liter of deionized water in a Waring blender for $30 \mathrm{sec}$. Prior to inoculation, each pot was watered to saturation and then two holes were made in the soil, one on either side of the plant. Ten $\mathrm{ml}$ of the mycelial inoculum (few or no sporangia or chlamydospores were present), either race 0 or race 1 , was poured into each hole, 20 $\mathrm{ml}$ per pot. The 3 non-inoculated control plants for each genotype were treated with distilled water.

Disease ratings and pathogen populations. Shoot disease development was rated visually on a daily basis, beginning 3 days after inoculation. Rating was based on a scale of 0 to 5: 0 indicated no symptoms, 1 indicated wilting, 2 indicated wilting and slight blackening of stem, 3 indicated wilting and stem blackening, 4 indicated wilting, stunting, and severe stem blackening, and 5 indicated a dead plant. Additionally, plant heights were taken at 4 weeks following inoculation. These heights were taken from the soil line to the tip of the last leaf. Fresh weight of plants from each treatment, including both shoots and washed roots, was recorded at the termination of the experiment (5 weeks following inoculation). At the same time, plant root systems were visually observed and given a numerical score estimating root health/pathogen damage. A score of 0 indicated no apparent root infection, 1 indicated slight stunting of roots, 2 indicated moderate stunting with some browning of roots, 3 indicated moderate stunting and severe browning, 4 indicated severe stunting and severe browning, and 5 indicated root systems that were completely destroyed by the pathogen.

The presence of $P$. parasitica var. nicotianae in soil was confirmed 5 weeks following inoculation by taking soil samples from the pots in which resistant and susceptible plants were grown. Samples were plated onto a semi-selective agar medium $(14,24)$ and pathogen populations were estimated by counting colonies that developed. Roots also were collected, and 20 root pieces per sample were surface sterilized in $10 \% \mathrm{NaOCl}$ for $1 \mathrm{~min}$ and plated on the selective medium to confirm presence of $P$. parasitica var. nicotianae.

\section{RESULTS}

High levels of black shank developed in the disease nursery in both years of the study, as evidenced by the reaction of the susceptible cultivar (Hicks), which was interplanted between test rows. Hicks was uniformly and severely stunted with a blackened stem and died early in each growing season. The absence of symptoms of black shank disease in C 371-G indicated that race 0 was the predominant race of $P$. parasitica var. nicotianae present in the disease nursery, and that race 1 was either absent or was present at very low levels.

In the field test, the $19 \mathrm{DH}$ lines from the NCTG 60 population segregated 9:10
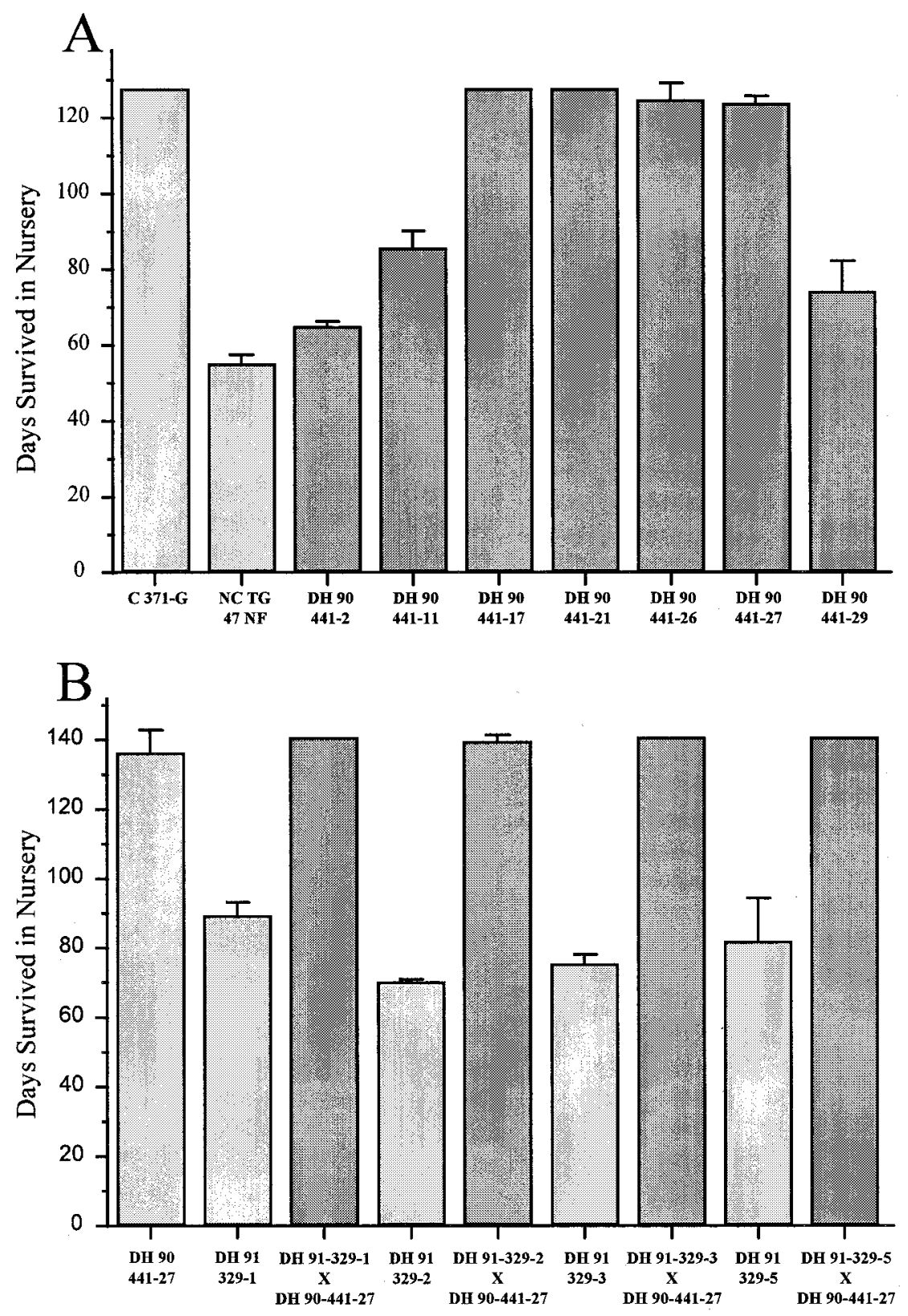

Fig. 3. (A) Disease response of non-flowering doubled haploid (DH) 90-441 lines evaluated in a black shank disease nursery. NCTG $47 \mathrm{NF}$ is the susceptible check breeding line and C 371-G is the resistant check cultivar. DH lines that survived greater than 100 days are considered highly resistant to Phytophthora parasitica var. nicotianae and homozygous for the $P h$ gene. Least significant difference $(\mathrm{LSD})_{0.05}=7.7$ for comparing experimental lines with resistant or susceptible check. (B) Disease nursery response of non-flowering tobacco lines and hybrids. DH 90-441-27 is a resistant breeding line and the DH 91-329 lines are susceptible breeding lines. Hybrids heterozygous for the $P h$ gene survived greater than 100 days following transplanting, similar to the resistant parental line DH 90-441-27. $\mathrm{LSD}_{0.05}=10.9$ for comparing hybrids with resistant and susceptible breeding lines. 
for very high resistance and a low level of resistance. This ratio did not differ significantly from a 1:1 segregation ratio (based on a chi-square analysis, $P$ value is 0.95 for $\chi^{2}=0.053$ ), and provides evidence that a single gene, hereby designated $P h$, confers the high level of resistance present in C $371-\mathrm{G}$ to race 0 of $P$. parasitica var. nicotianae. Based on their field performance, 10 of these $19 \mathrm{DH}$ lines, 5 from each resistance category, were chosen for subsequent greenhouse testing (Fig. 2).

Prior breeding experience with nonflowering (NF) tobacco cultivars has shown that the Fla 301 resistance present in these cultivars does not provide a high level of black shank resistance. Addition of the $P h$ gene to the NF lines provided complete resistance to race 0 of $P$. parasitica var. nicotianae. Of 7 doubled haploid lines obtained from the $F_{1}$ hybrid between NCTG 47 NF and C 371-G, 4 were highly resistant to $P$. parasitica var. nicotianae when evaluated in a naturally infested black shank nursery in 1991 (Fig. 3A). Although the sample size is small, it also follows a bimodal segregation. The 4 resistant lines survived an average of 126 (+/-2) days. The remaining 3 doubled haploid lines had a low level of resistance to $P$. parasitica var. nicotianae and survived an average of $75(+/-2)$ days, similar to the parental NF line. Additional testing in the 1992 disease nursery confirmed that a doubled haploid from this array, DH 90441-27, had a very high level of resistance to $P$. parasitica var. nicotianae, surviving an average of 137 (+/-3) days (Fig. 3B). This line is homozygous for the C 371-G resistance gene. The DH 91-329 lines represented in Figure 3B were derived from a three-way-cross of NF lines that were black shank susceptible. All DH 91-329 lines succumbed to $P$. parasitica var. nicotianae between 70 and 89 days after transplanting. In all 4 hybrid combinations between resistant line DH 90-441-27 and a susceptible DH 91-329 line, the hybrid survived the complete growing season (141 days) and was as resistant to $P$. parasitica var. nicotianae as DH 90-441-27. All of these hybrids are heterozygous for the superior resistance from C 371-G, which indicates that the $P h$ gene is completely dominant, providing equal resistance in both the homozygous and heterozygous states.

The greenhouse screening technique was reliable in identifying responses to races of $P$. parasitica var. nicotianae. Significant differences in disease incidence and severity were observed following inoculation with race 0 on lines with or without the $P h$ gene (least significant difference ${ }_{0.05}=0.5$; Fig. 4). The race 0 isolate caused characteristic black shank symptoms as soon as 5 days following inoculation of DH lines that lacked the $P h$ gene. Lines with the $P h$ gene that were resistant to the disease in the field showed very low severities of disease in the greenhouse. The mean shoot disease severity rating of the resistant $\mathrm{DH}$ lines (1.1) was significantly lower than the mean shoot disease score (3.1) of susceptible DH lines (Table 1). NCTG 60, which is homozygous for C 371-G resistance, had very high resistance to race 0 of $P$. parasitica var. nicotianae in the greenhouse (Fig. 3), as did the $\mathrm{F}_{1}$ hybrid between NCTG 60 and $\mathrm{K} 326$ which is heterozygous for the $\mathrm{C}$ 371-G resistance mechanism (data not shown). These data again indicate that

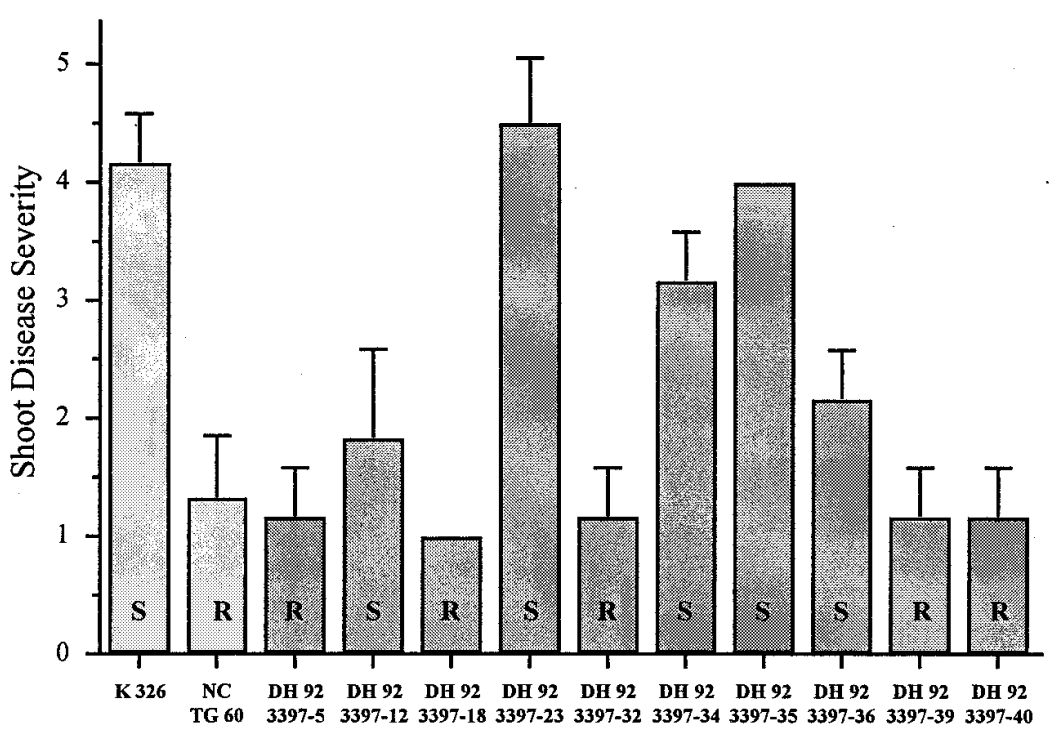

Fig. 4. Tobacco lines evaluated in the greenhouse for their response to race 0 of Phytophthora parasitica var. nicotianae. Lines with a disease severity greater than 1.5 were considered to have only partial resistance from Fla 301, while lines with a disease severity less than 1.5 were considered to have high resistance derived from the $P h$ gene. An ' $S$ ' designation within the bar indicates susceptibility in a black shank disease nursery, while an ' $R$ ' designation indicates resistance in a disease nursery. resistance conferred by the $P h$ gene in $\mathrm{C}$ $371-\mathrm{G}$ is completely dominant. No disease symptoms were observed in the non-inoculated block.

Plant response to race 1 of $P$. parasitica var. nicotianae was similar across all genotypes studied. Average shoot disease severity scores were fairly uniform, with line means ranging from 1.8 to 2.8 , and differences were not significant among lines (Table 1). There was no association between presence of the $P h$ gene, or high race 0 resistance, with disease response to race 1 for the sample of lines evaluated. Genotypes without the $P h$ gene showed the same levels of disease as genotypes with it.

Height differences among plants were noted soon after inoculation. Mean plant height was $43.4(+/-2.5) \mathrm{cm}$ for the noninoculated plants. Plants inoculated with race 0 averaged $33.6(+/-4.6) \mathrm{cm}$, while plants inoculated with race 1 had an average height of $24.4(+/-1.9) \mathrm{cm}$. Race 1, though not inducing some of the more characteristic black shank symptoms such as wilting or stem blackening in the greenhouse, had a significantly greater influence than race 0 on plant height.

Weight differences also were observed among treatments at 5 weeks post-inoculation, with significant weight reductions in both inoculated blocks compared to noninoculated controls (Table 1). Average weight of non-inoculated control lines was 79.9 g per plant; race 0 and race 1 inoculated plants averaged $65 \%$ and $56 \%$ of non-inoculated control lines, respectively. Genotypes expressing resistance to race 0 were not significantly different from noninoculated controls when inoculated with race 0 . Conversely, susceptible genotypes produced $42 \%$ of the fresh weight of noninoculated controls when inoculated with race 0 . Weights of genotypes were not different when inoculated with race 1 . Root rot ratings at 5 weeks postinoculation also indicated differences in response to races of the pathogen. Scores for roots of inoculated blocks were reduced $78 \%$ and $76 \%$ from the average score of the non-inoculated roots for races 0 and 1 , respectively (Table 1). As with height and weight assessments, greater variation was seen in root scores with race 0 due to segregation for resistance to $P$. parasitica var. nicotianae. Average root score in highly resistant genotypes was $95 \%$ of non-inoculated roots, compared to $57 \%$ in genotypes with low resistance. Roots from race 1 -inoculated plants showed a relatively high level of root infection that was uniform across all genotypes.

Soil samples from pots infested with race 0 that contained susceptible plants averaged 150 propagules/g of soil, and $75 \%$ of the root samples were positive for $P$. parasitica var. nicotianae. In comparison, plants with the $P h$ resistance gene had healthy, uninfected roots and no propagules of the pathogen were recovered from soil 
samples. In pots infested with race $1,68 \%$ of the lines resistant to race 0 had root systems infected with $P$. parasitica var. nicotianae, and propagule levels in soil ranged from 30 to 93 propagules/g of soil. The pathogen was not recovered from noninoculated plants.

\section{DISCUSSION}

Prior efforts to verify the origin of resistance in C 371-G were unsuccessful (8). This study has demonstrated the presence of a qualitative resistance in C 371-G. We propose that the gene is derived from an interspecific source, because no complete resistance genes to $P$. parasitica var. nicotianae have been identified in N. tabacum. This conclusion has since been supported by other researchers, who suggest that $\mathrm{C}$ 371-G resistance closely resembles the resistance to race 0 obtained from $N$. longiflora or $N$. plumbaginifolia $(5,7)$. The burley breeding line L 8, which possesses $N$. longiflora resistance, also provides very high resistance to race 0 but no resistance to race 1 of $P$. parasitica var. nicotianae $(16,29)$. Both genes also show complete dominance in the heterozygous condition. Further evaluations, including a comparison between the black shank resistance gene in L 8 and the $P h$ gene from C 371-G, must be completed to ascertain whether $N$. longiflora, $N$. plumbaginifolia, or another unidentified genotype is the source of the C 371-G $P h$ gene.

Complete inbreeding resulting from the doubled haploid technologies employed in these studies contributed greatly to the identification of the $P h$ gene. When two parental genotypes that differ in disease resistance are hybridized and a $\mathrm{DH}$ array is developed from the $F_{1}$ hybrid, all genetic variability for resistance is partitioned into differences among DH lines; plant to plant genetic variation within DH lines is zero. This permitted the DH lines from the K326 $\times$ NCTG 60 hybrid to be partitioned into two genetic groups; $P h / P h$ with high resistance to race 0 , and $p h / p h$ with only partial resistance.

In general, race 0 isolates of $P$. parasitica var. nicotianae are more aggressive than isolates of race 1 (3). In our green-

Table 1. Disease severity and plant weight of tobacco plants following challenge with race 0 or race 1 of Phytophthora parasitica var. nicotianae in the greenhouse

\begin{tabular}{|c|c|c|c|}
\hline Treatment & Shoot disease severity ${ }^{a}$ & Weight (g/plant) & Root rot severity $^{b}$ \\
\hline Race 0 & 2.1 & 52.1 & 3.3 \\
\hline Resistant & 1.1 & 70.7 & 1.8 \\
\hline Susceptible & 3.1 & 33.4 & 4.9 \\
\hline Resistant vs. susceptible $^{c}$ & $* *$ & ** & ** \\
\hline Race 1 & 2.4 & 44.6 & 3.5 \\
\hline Resistant vs. susceptible $^{c}$ & $\mathrm{~ns}$ & $\mathrm{~ns}$ & ns \\
\hline Non-inoculated & 0.0 & 79.9 & 1.4 \\
\hline
\end{tabular}

${ }^{a}$ Shoot disease score based on a scale of 0 to 5 , with 0 indicating no symptoms of black shank and 5 equal to death of the aboveground plant.

${ }^{\mathrm{b}}$ Root score based on a scale of 0 to 5 , with 0 implying no symptoms of root infection and 5 equal to a completely destroyed root system.

${ }^{c}$ Significant at $P_{0.01}(* *)$ or not significant (ns) by analysis of variance. nursery space for only those genotypes carrying the highest level of resistance. With limited access to disease nurseries, such a technique would be highly desirable. Combining high Fla 301 resistance with the $P h$ gene should provide resistance to both races of $P$. parasitica var. nicotianae and should be the goal of future breeding programs.

\section{ACKNOWLEDGMENTS}

We thank John S. Tysinger for technical assistance.

\section{LITERATURE CITED}

1. Apple, J. L. 1957. Pathogenic, cultural, and physiological variation within Phytophthora parasitica var. nicotianae. Phytopathology 47:733-740.

2. Apple, J. L. 1962. Physiological specialization within Phytophthora parasitica var. nicotianae. Phytopathology 52:351-354.

3. Apple, J. L. 1967. Occurrence of race 1 of Phytophthora parasitica var. nicotianae in North Carolina and its implications in breeding for disease resistance. Tob. Sci. 11:79-83.

4. Burk, L. G., Gerstel, D. U., and Wernsman, E. A. 1979. Maternal haploids of Nicotiana tabacum L. from seed. Science 206:585.

5. Campbell, K. G., and Wernsman, E. A. 1994. Selection among haploid sporophytes for resistance to black shank in tobacco. Crop Sci. 34:662-667.

6. Crews, J. W., Wills, W. H., and LaPrade, J. L. 1964. Black shank disease reactions of six flue-cured tobacco varieties and the $\mathrm{F}_{1}$ hybrids among them. Tob. Sci. 8:128-132.

7. Csinos, A. S., and Bertrand, P. F. 1994. Distribution of Phytophthora parasitica var. nicotianae races and their sensitivity to metalaxyl in Georgia. Plant Dis. 78:471-474.

8. Csinos, A. S., and Whitty, E. B. 1995 Evaluation of Coker 371-Gold parentage for resistance to Phytophthora parasitica var. nicotianae. (Abstr.) Tobacco Workers Conf., Tampa, Fl.

9. English, J. T., and Mitchell, D. J. 1989. Use of morphometric analysis for characterization of tobacco root growth in relation to infection by Phytophthora parasitica var. nicotianae. Plant Soil 113:243-249.

10. Ferrin, D. M., and Mitchell, D. J. 1986. Influence of initial density and distribution of inoculum on the epidemiology of tobacco black shank. Phytopathology 76:1153-1158.

11. Hendrix, J. W., and Apple, J. L. 1967. Stem resistance to Phytophthora parasitica var nicotianae in tobacco derived from Nicotiana longiflora and N. plumbaginifolia. Tob. Sci. 11:148-150.

12. Jones, K. J. 1990. Components of resistance in Nicotiana tabacum to Phytophthora parasitica var. nicotianae. Ph. D. Thesis, North Carolina State University. Raleigh.

13. Jones, K. J., and Shew, H. D. 1995. Early season root production and zoospore infection of cultivars of flue-cured tobacco that differ in levels of partial resistance to Phytophthora parasitica var. nicotianae. Plant Soil 172:5561.

14. Kannwischer, M. E., and Mitchell, D. J. 1978. The influence of a fungicide on the epidemiology of black shank of tobacco. Phytopathology 68:1760-1765.

15. Kasperbauer, M. J., and Collins, G. B. 1972 Reconstitution of diploids from leaf tissue of anther-derived haploids in tobacco. Crop Sci. 12:98-101.

16. Litton, C. C., Collins, G. B., and Legg, P. D. 1970. Reaction of Nicotiana tabacum and other $N$. species to race 0 and 1 of Phytophthora parasitica var. nicotianae. Tob. 
Sci. 14:128-130

17. Lucas, G. B. 1975. Diseases of tobacco, 3rd ed. Biological Consulting Associates, Raleigh, NC.

18. McIntyre, J. L., and Taylor, G. S. 1978. Race 3 of Phytophthora parasitica var. nicotianae. Phytopathology 68:35-38.

19. Nielsen, M. T. 1995. CORESTA Black Shank Collaborative Study. Pages 36-41 in: CORESTA Information Bulletin, 1995-1. Paris, France.

20. Nusbaum, C. J. 1952. Host-parasite relations of Phytophthora parasitica var. nicotianae in roots of resistant and susceptible tobacco varieties. Phytopathology 42:286.

21. Powell, N. T. 1956. Host parasite relations of Phytophthora parasitica var. nicotianae in roots of resistant and susceptible tobacco varieties, Nicotiana longiflora and Nicotiana plumbaginifolia. MS Thesis, North Carolina State University, Raleigh.

22. Prinsloo, G. C., and Pauer, G. D. C. 1973. Die identifikasie van rasse van Phytophthora nicotianae (B de Haan) nicotianae wat in Suid Afrika voorkom. Phytophylactica 6:217220.

23. Rufty, R. C., Wernsman, E. A., and Gooding, G. V., Jr. 1987. Use of detached leaves to evaluate tobacco haploids and doubled haploids for resistance to tobacco mosaic virus, Meloidogyne incognita, and Pseudomonas syringae pv. tabaci. Phytopathology 77:60-62.

24. Shew, H. D. 1983. Effects of soil matric potential on infection of tobacco by Phytophthora parasitica var. nicotianae. Phytopathology 73:1160-1163.

25. Shew, H. D. 1987. Effect of host resistance on spread of Phytophthora parasitica var. nicotianae and subsequent development of tobacco black shank under field conditions. Phytopathology 77:1090-1093.

26. Shew, H. D. 1991. Black Shank. Pages 17-21 in: Compendium of Tobacco Diseases. H. D. Shew and G. B. Lucas, eds. American Phytopathological Society Press, St. Paul, MN.

27. Shew, H. D., and Shew, B. B. 1994. Host resistance. Pages 244-275 in: Epidemiology and Management of Root Diseases. C. L. Campbell and D. M. Benson, eds. SpringerVerlag, Berlin.

28. Silber, G., and Heggestad, H. E. 1963. Comparative black shank resistance of Beinhart 1000 (Quin Diaz), N.C. 5346, and Rg in $\mathrm{F}_{1}$ generation involving various tobacco types. Tob. Sci. 7:144-147.

29. Stokes, G. W., and Litton, C. C. 1966. Source of black shank resistance in tobacco and host reaction to races 0 and 1 of Phytophthora parasitica var. nicotianae. Phytopathology 56:678-680.

30. Tedford, E. C., Miller, T. L., and Nielsen, M T. 1990. A detached-leaf technique for detecting resistance to Phytophthora parasitica var. nicotianae in tobacco. Plant Dis. 74:313316.

31. Tisdale, W. S. 1931. Development of strains of cigar wrapper tobacco resistant to black shank (Phytophthora nicotianae Breda de Haan). Univ. Florida Agric. Exp. Stn. Bull. 226.

32. Wernsman, E. A., and Matzinger, D. F. 1980 Mammoth genotypes and tobacco management regimes for reduced production of downstalk tobaccos. Agron. J. 72:1047-1050.

33. Wernsman, E. A., Matzinger, D. F., and Powell, N. T. 1974. Genetic investigations of intraspecific sources of black shank resistance in tobacco. Tob. Sci. 18:15-18.

34. Wills, W. H. 1971. A comparison of black shank resistance of tobacco measured in inoculated whole plants and excised leaf tissue. Tob. Sci. 15:47-50.

35. Wills, W. H., and Moore, L. D. 1971. Response of some cultivars and lines of tobacco to stem inoculation with Phytophthora parasitica var. nicotianae. Tob. Sci. 15:51-53. 